\title{
Single- and double-electron transfer reactions of ground and metastable state $\mathbf{A r}^{2+}$ ions
}

\author{
G C Shields and T F Moran \\ School of Chemistry, Georgia Institute of Technology, Atlanta, Georgia 30332, USA
}

Received 18 April 1983, in final form 14 June 1983

\begin{abstract}
Electron transfer cross sections have been measured for reactions of $\mathrm{Ar}^{2+}$ ions with $\mathrm{Ar}, \mathrm{N}_{2}, \mathrm{O}_{2}, \mathrm{CO}, \mathrm{CO}_{2}, \mathrm{CH}_{4}$ and $\mathrm{C}_{2} \mathrm{H}_{6}$. Time-of-flight techniques have been used to with $\mathrm{Ar}, \mathrm{N}_{2}, \mathrm{O}_{2}, \mathrm{CO}, \mathrm{CO}_{2}, \mathrm{Cr}^{0}$ and fast $\mathrm{Ar}^{+}$products from single- and double-electron transfer processes involving $\mathrm{Ar}^{2+}$ ions with 4.0 to $7.0 \mathrm{keV}$ impact energies. Incident $\mathrm{Ar}^{2+}$ ions have been produced by controlled electron impact ionisation of argon atoms. Reactions have been examined as a function of ionising electron energy and cross sections determined for ground state $\mathrm{Ar}^{2+}\left({ }^{3} \mathrm{P}\right)$ ions. Charge transfer cross sections have been determined to be in the range of $3 \times 10^{-16} \mathrm{~cm}^{2}$ for the systems examined. Double-electron transfer cross sections are the same order of magnitude as those measured for the corresponding single-electron transfer reactions. The state distribution of our reactant ion beam has been estimated and electron transfer cross sections obtained for single- and double-electron transfer reactions of metastable $\mathrm{Ar}^{2+}$ ions. The magnitudes of electron transfer cross sections in individual systems are similar for both ground and metastable state $\mathrm{Ar}^{2+}$ reactions.
\end{abstract}

\section{Introduction}

Reactions of multicharged ions have received attention from investigators pursuing the development of experimental and theoretical collision physics as well as from groups examining the influence of these reactions in: the operation of energy efficient fusion plasmas; the description of astrophysical plasmas; and the production of short wavelength lasers. Much of the research work involving multicharged ions has been directed toward the measurement of total cross sections for single and multi-electron transfer processes (Janev and Presnyakov 1981). Total cross sections for electron transfer can be quite large for reactions involving multicharged ions and the products can be highly excited. Product ion state distributions from single-electron transfer reactions of doubly-charged ions have been obtained recently by optical spectroscopic methods (Barrett and Leventhal 1981, Matsumoto et al 1982, Kadota et al 1982) and by techniques involving translational spectroscopy (Kamber et al 1982). Several investigations have been carried out to examine the effects of incident ion states on electron transfer reactions of thermal energy ions (Johnsen and Biondi 1978a, b, 1979 , Smith et al 1979). Electronic state selection of thermal energy reactant ions has been achieved by taking advantage of different ion-state reactivities with various drift-tube carrier gases which served to deplete certain incident ion states prior to reaction with target gases. Although thermal reactions of doubly-charged ions have

(C) 1983 The Institute of Physics 
been shown to depend strongly on the incident ion state, little work has been done to examine the effect of incident ion electronic states on reactions at $\mathrm{keV}$ incident ion energies. It is the purpose of this paper to report results of an investigation to determine one- and two-electron transfer cross sections in collisions of 4-7 keV ground and metastable state $\mathrm{Ar}^{2+}$ ions with various molecules.

\section{Experimental}

Time-of-flight techniques have been employed to measure fast neutral and ionic products resulting from electron transfer reactions. The apparatus and techniques have been described and used previously to obtain cross sections for formation of fast neutral products from electron transfer reactions of singly-charged ions (Moran and Wilcox 1978). In brief, reactant $\mathrm{Ar}^{2+}$ ions have been produced by controlled electron impact ionisation of high-purity argon gas. Ionising electrons have been emitted from a directly-heated thorium oxide filament and accelerated into the ion source by a voltage controllable from 2 to $100 \mathrm{~V}$. The electron beam intensity has been kept constant during each measurement by means of a regulated filament current supply having an electron trap filament current feedback loop. Several plates with holes and an external magnet have been used to collimate the electron beam and ensure passage of a well-defined electron beam through the ion source. The absolute energy of the electron beam has been determined from applied voltages and checked by measurement of known ionisation energies of several rare gases and diatomic molecules. The electron-beam energy has been monitored during each experiment by measurement of the $\mathrm{Ar}^{2+}$ ionisation energy.

Reactant $\mathrm{Ar}^{2+}$ ions produced in the ion source have been drawn out of the ion source by a fast rising pulse and then accelerated to terminal velocities. The fully accelerated ion beam next entered a static gas collision region where electron transfer reactions have taken place. The pressures of high-purity target gas molecules introduced into the collision region have been continuously monitored by an ion gauge. This gauge has been baffled to prevent transport of charged species from the gauge into the collision region. The ion gauge has been calibrated against a capacitance manometer, the accuracy of which has been checked by a cooled McLeod gauge with data corrected for thermal transpiration.

Incident $\mathrm{Ar}^{2+}$ and fast $\mathrm{Ar}^{+}, \mathrm{Ar}^{0}$ products from electron transfer reactions proceeded through a $1 \mathrm{~m}$ drift region and have been collected on the cathode of a gated electron multiplier. The final $0.2 \mathrm{~m}$ segment of drift region has been insulated from the first segment so that it has been possible to retard the ions as they passed from the first drift region to the second. In the absence of a retarding voltage on the second drift region, the reactant $\mathrm{Ar}^{2+}$ and fast $\mathrm{Ar}^{+}, \mathrm{Ar}^{0}$ products have approximately equal arrival times at the collector; an arrival time characteristic of $m / e 20 \mathrm{u}$ ions. However, application of a deceleration voltage to the second drift region gave the reactant $\mathrm{Ar}^{2+}$ a longer arrival time than the fast $\mathrm{Ar}^{+}$products without affecting the $\mathrm{Ar}^{0}$ arrival time. In this mode of operation, three separate peaks have been obtained in the time-offlight spectrum. These peaks correspond to; reactant $\mathrm{Ar}^{2+}$ ions, fast $\mathrm{Ar}^{+}$, and $\mathrm{Ar}^{0}$ products from the reactions

$$
\mathrm{Ar}^{2+}+\mathrm{Y}\left\{\begin{array}{l}
\mathrm{Ar}^{+}+(\mathrm{Y})^{+} \\
\mathrm{Ar}^{0}+(\mathrm{Y})^{2+}
\end{array}\right.
$$


Secondary electron emission coefficients of the cathode, determined using standard techniques (Hayden and Utterback 1964), have been found to be approximately equivalent for $\mathrm{Ar}^{+}$and $\mathrm{Ar}^{0}$. Equal emission coefficients have resulted in equivalent collection efficiencies for both $\mathrm{Ar}^{0}$ and $\mathrm{Ar}^{+}$fast products over the kinetic energy range of our experiments.

Two-electron transfer processes in $\mathrm{Ar}^{2+}+\mathrm{Ar}$ reactions have been extensively studied at low keV kinetic energies. The cross sections obtained in previous investigations are illustrated in figure 1 . These data from different groups are in moderate accord with each other. The full curve from 4 to $7 \mathrm{keV}$ energy represents an average of the cross sections. We have chosen to measure relative cross sections in our present investigation and have put our data on an absolute basis using the average value (line) of cross sections measured previously in the $4-7 \mathrm{keV}$ ion impact energy range.

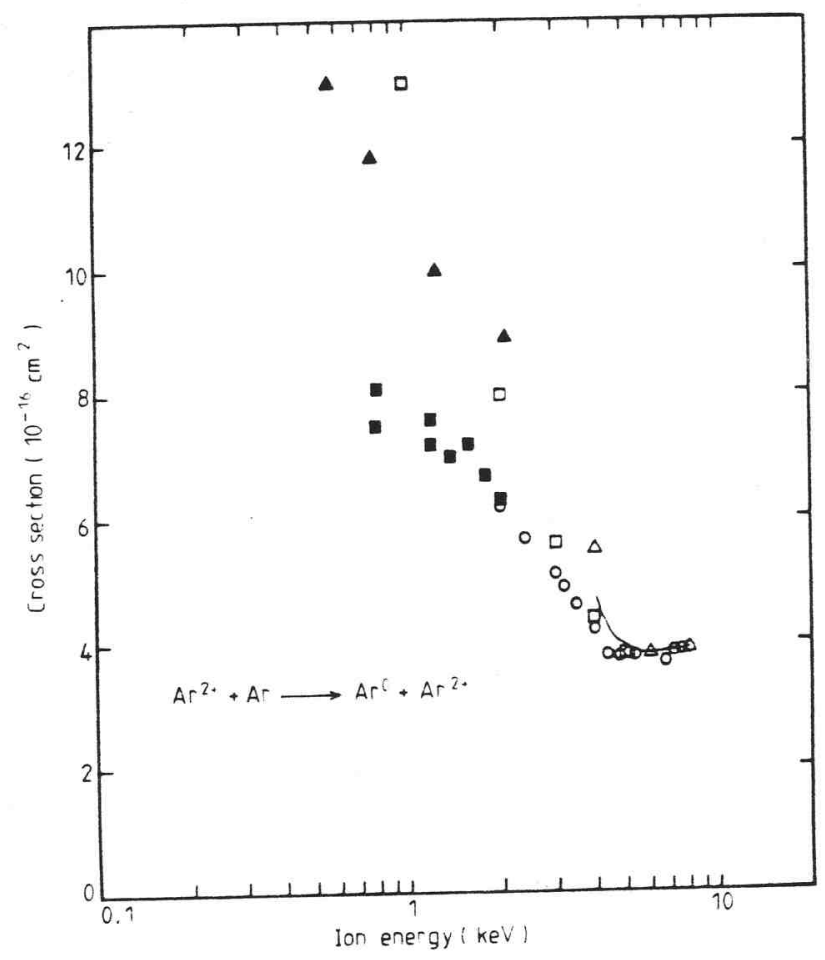

Figure 1. Total charge transfer cross sections $\left(10^{-16} \mathrm{~cm}^{2}\right)$ for production of fast neutral $\mathrm{Ar}^{0}$ as a function of reactant ion kinetic energy $(\mathrm{keV})$ in $\mathrm{Ar}^{2+}+\mathrm{Ar}$ interactions. Experimental data given in this figure are from: $O$, Cosby and Moran (1972): $\triangle$, Kaneko et al (1981); Hasted and Hussain (1964); $\square$, Latypov et al (1969); $\mathbf{\square}$, McGowan and Kerwin (1967).

\section{Results and discussion}

\subsection{Reaction energetics}

The minimum energy required to produce $\mathrm{Ar}^{2+}\left({ }^{3} \mathrm{P}_{J}\right)$ ions from electron impact ionisation of ground-state $\operatorname{Ar}\left({ }^{1} \mathrm{~S}_{0}\right)$ atoms is $43.39 \mathrm{eV}$ whereas the corresponding energy to 
form $\mathrm{Ar}^{+}\left({ }^{2} \mathrm{P}_{J}\right)$ ions is $15.76 \mathrm{eV}$ (Moore 1949). The large energy difference between single- and double-ionisation energies results in a large energy defect, $\Delta E$, for the single-electron transfer reactions

$$
\mathrm{Ar}^{2+}+\mathrm{Ar} \rightarrow \mathrm{Ar}^{+}+\mathrm{Ar}^{+}+\Delta E
$$

involving ground-state species. The magnitude of this energy defect is reduced for reactions producing excited-state products. Energy defects for the various $\mathrm{Ar}^{+}(n, l, J)$ products are illustrated in figure 2 for reactions involving $\mathrm{Ar}^{2+}\left({ }^{3} \mathrm{P}_{\mathrm{J}},{ }^{1} \mathrm{D}_{2}\right.$ and $\left.{ }^{1} \mathrm{~S}_{0}\right)$ reactant ions. The metastable $\mathrm{Ar}^{2+}\left({ }^{1} \mathrm{D}_{2}\right.$ and $\left.{ }^{1} \mathrm{~S}_{0}\right)$ states are present in the reactant ion beam and their relative abundances are discussed in $\S 3.2$. The high density of product ion states gives rise to a near continuum of endothermic product channels.

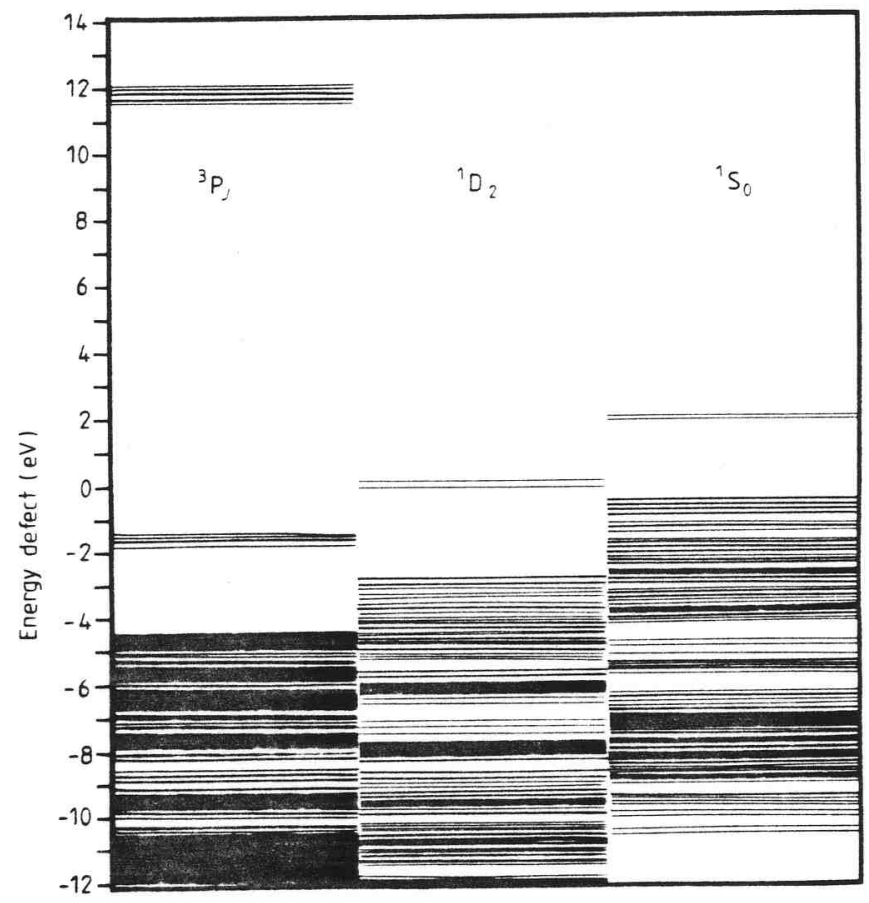

Figure 2. Energy defects $(\mathrm{eV})$ for the reactions $\left.\operatorname{Ar}^{2+}(\mathrm{X})+\operatorname{Ar}^{1} \mathrm{~S}_{0}\right) \rightarrow \operatorname{Ar}^{-}(n, l, J)+\operatorname{Ar}^{-}\left(n^{\prime}\right.$, $\left.l^{\prime}, J^{\prime}\right)$ where $\mathrm{X}={ }^{3} \mathrm{P}_{J},{ }^{1} \mathrm{D}_{2},{ }^{1} \mathrm{~S}_{0}$.

The potential energy of the incident $\mathrm{Ar}^{2+}\left({ }^{3} \mathrm{P}_{J}\right)+\operatorname{Ar}\left({ }^{1} \mathrm{~S}_{0}\right)$ reactant channel follows the ion-induced dipole interaction

$$
V=-2 e^{2} \alpha(\operatorname{Ar}) / R^{4}
$$

where $\alpha$ is the polarisability of the target $\operatorname{Ar}\left({ }^{1} \mathrm{~S}_{0}\right)$ atoms. The various $\operatorname{Ar}^{+}(n, l, J)+$ $\operatorname{Ar}^{+}\left(n^{\prime}, l^{\prime}, J^{\prime}\right)$ product channels have been described in terms of a combination of Coulomb repulsive and ion-induced dipole attractive potentials of the form suggested by Kamber et al (1982)

$$
V=e^{2} / R-e^{2}\left(\alpha\left(\mathrm{Ar}^{+}\right)+\alpha\left(\mathrm{Ar}^{+}\right)\right) / 2 R^{4}-\Delta E
$$

where $\alpha$ is the polarisability of $\mathrm{Ar}^{+}$products and $\Delta E$ is the energy defect of individual 
product channels. These approximate potential energy curves for incoming reactants and outgoing products of single-electron transfer reactions are shown in figure 3 by chain and full curves respectively. Diabatic transitions between the reactant and exothermic product channels are possible at an internuclear separation of approximately $1.7 \times 10^{-8} \mathrm{~cm}$. Two-electron transfer product channels which form $\mathrm{Ar}^{2+}\left({ }^{1} \mathrm{D}_{2}\right.$ and ${ }^{1} \mathrm{~S}_{0}$ states) are shown by the broken curves. Although these channels are forbidden as products by the Wigner spin-conservation rule $(\Delta S=0)$, they are illustrated as possible product channels since this rule is not strictly obeyed in collisions of the heavier rare-gas systems (Kamber et al 1982, Moore 1974).

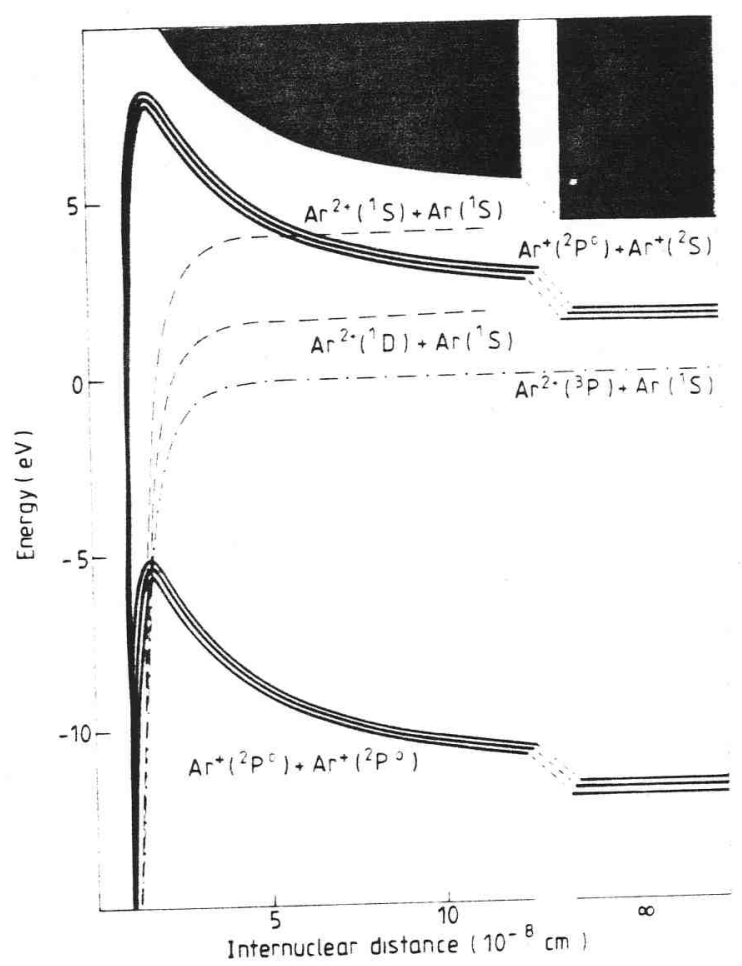

Figure 3. Potential energy curves for $\operatorname{Ar}^{2+}\left({ }^{3} \mathrm{P}_{J}\right)+\operatorname{Ar}\left({ }^{1} \mathrm{~S}_{0}\right)$ interactions as a function of internuclear distance. The reactant channel is given by the chain curve. Possible product channels for two-electron transfer are given by the broken curves and the chain curve for the resonant reaction. The full curves represent single-electron transfer channels which have $\mathrm{Ar}^{+}(n, l, J)+\mathrm{Ar}^{+}\left(n^{\prime}, l^{\prime}, J^{\prime}\right)$ products.

A total of nine resonant and near-resonant two-electron transfer reaction channels are available for the $\mathrm{Ar}^{2+}\left({ }^{3} \mathrm{P}_{J}\right)$ state where $J$ equals 2,1 and 0 . Only one resonant channel exists for the two-electron transfer processes involving $\mathrm{Ar}^{2+}\left({ }^{1} \mathrm{D}_{2}\right)$ ions. Likewise there is only one resonant channel for the two-electron transfer reactions of $\mathrm{Ar}^{2+}\left({ }^{1} \mathrm{~S}_{0}\right)$ ions.

It has been suggested (Salzborn and Müller 1980) that the observed total cross section for one-electron charge transfer in reaction (3) occurs by means of the exothermic channel. Single-electron transfer rate coefficients for reactions of doublycharged ions with rare-gas atoms have been measured at thermal energies by Smith 
et al (1980). They interpreted their data on the basis of a curve-crossing model and showed that when reactant curves cross exothermic single-electron transfer product curves in the $2-7 \times 10^{-8} \mathrm{~cm}$ internuclear distance range there is a high probability for single-electron transfer. In addition to the exothermic product channel crossings invoked to explain the thermal energy data, endothermic channel crossings at small internuclear distances must also be considered for $\mathrm{keV}$ incident ion energies. Energy analysis of $\mathrm{Ar}^{+}$products from reaction (3) carried out by Ast et al (1975) indicates that endothermic channels dominate reactive scattering in the forward direction. Their data are reproduced by the full curve in figure 4 . Energy defects for all possible reaction channels have been computed for reactant $\mathrm{Ar}^{2+}$ ions in the ${ }^{3} \mathrm{P}_{J},{ }^{1} \mathrm{D}_{2}$ and ${ }^{1} \mathrm{~S}_{0}$ states. The number of reaction channels having energy defects within $0.1 \mathrm{eV}$ of each other has been tabulated and the total weighted sum plotted as a function of energy defect. This sum, obtained by a 9:5:1 weighting of the respective ${ }^{3} \mathrm{P}_{J},{ }^{1} \mathrm{D}_{2}$ and ${ }^{1} \mathrm{~S}_{0}$ state reaction channels, is represented by the full vertical lines at $0.1 \mathrm{eV}$ increments in figure 4 . The experimental curve extends over a wide range of energy defects and indicates that a large number of possible product channels are involved in reaction (3). The maximum in the curve suggests a high probability for endothermic reactions having energy defects ranging from -5 to $-9 \mathrm{eV}$.

Replacement of target atoms by molecules increases the number of possible product channels significantly. This is illustrated in figure 5 where potential energy curves for the reactions

$$
\operatorname{Ar}^{2+}\left({ }^{3} \mathrm{P}_{J}\right)+\mathrm{N}_{2}\left(\mathrm{X}^{1} \Sigma_{\mathrm{g}}, r=0\right) \longrightarrow \operatorname{Ar}^{+}(n, l, J)+\left(\mathrm{N}_{2}^{+}\right)
$$

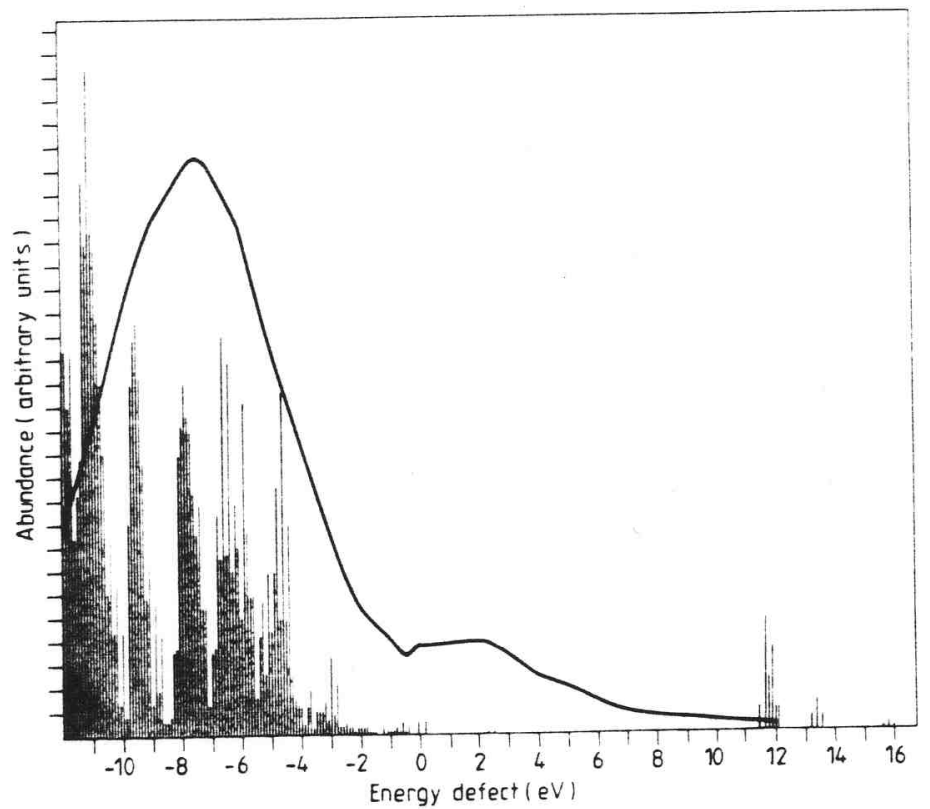

Figure 4. Fast $\mathrm{Ar}^{+}$product ion kinetic energy distribution measured by Ast et al (1975) is displayed by the full curve. Energy defects for various $\mathrm{Ar}^{+}+\mathrm{Ar}^{+}$product channels are summed together and displayed as vertical lines in $0.1 \mathrm{eV}$ energy increments. These defects for various $\mathrm{Ar}^{+}+\mathrm{Ar}^{+}$product channels are weighted according to the statistical population of $\mathrm{Ar}^{2+}$ ion states $\left({ }^{3} \mathrm{P}_{J},{ }^{1} \mathrm{D}_{2},{ }^{1} \mathrm{~S}_{0}\right)$ in the reactant ion beam. 


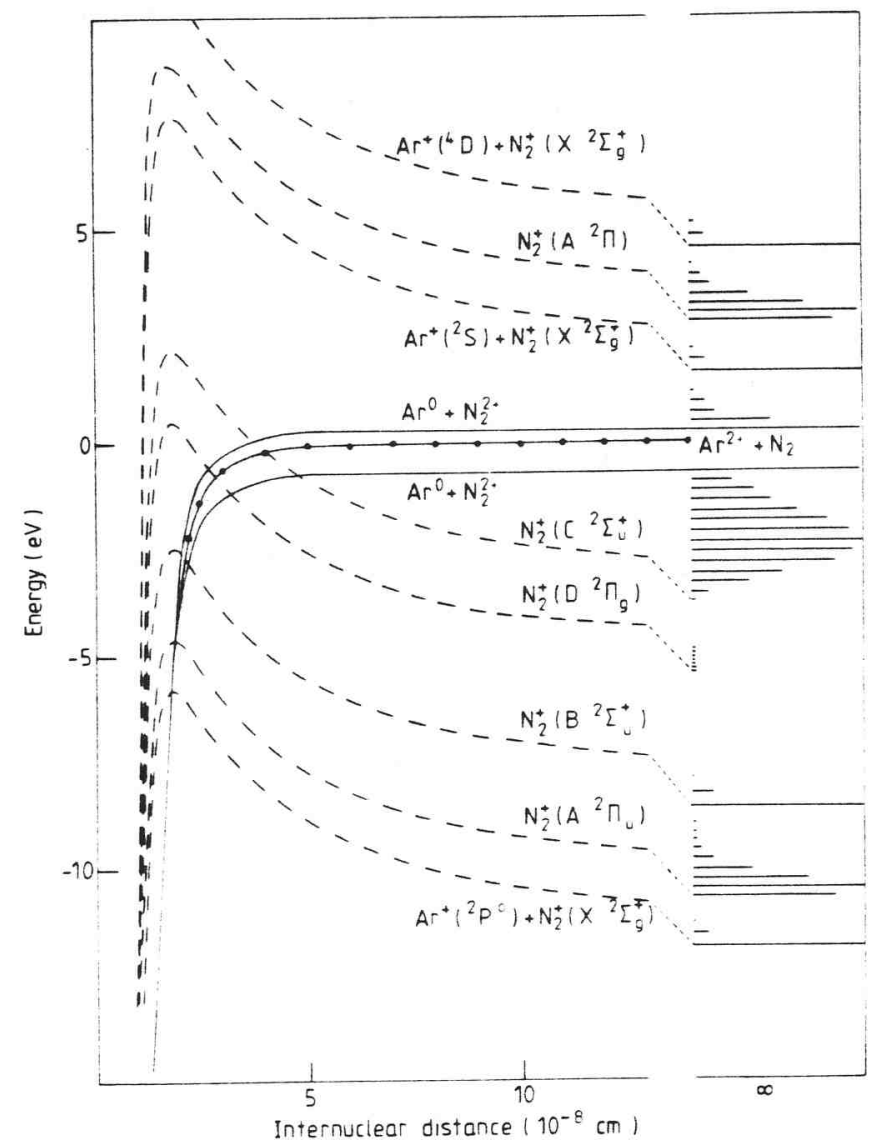

Figure 5. Potential energy curves for $\mathrm{Ar}^{2+}\left({ }^{3} \mathrm{P}_{J}\right)+\mathrm{N}_{2}\left(\mathrm{X}^{1} \Sigma_{\mathrm{g}}^{+}, v=J=0\right)$ interactions as a function of ion-molecule separation distance. The reactant channel is given by the curve with full circles. Broken lines represent single-electron transfer channels which have $\mathrm{Ar}^{+}+\mathrm{N}_{2}^{+}(v=J=0)$ products in the designated states. The full lines on the right-hand side of the figure illustrate the square of vibrational overlaps for vertical $N_{2}\left(X{ }^{1} \Sigma_{\varepsilon}\right.$. $v=J=0) \rightarrow \mathrm{N}_{2}^{+}(\mathrm{X}, \mathrm{A}, \mathrm{B}, \mathrm{C}, \mathrm{D}, v)$ and $\mathrm{N}_{2}^{2+}(v)$ Franck-Condon transitions. Full curves represent the two-electron transfer channels.

are given as a function of ion-molecule separation distance $R$. The potential energies for the various reaction channels at $R=\infty$ are illustrated by the horizonal lines on the right side of this figure. The broken curves represent potential energies for single-electron transfer channels in which $v=0 \mathrm{~N}_{2}^{+}$ions in the $\mathrm{X}^{2} \Sigma_{\mathrm{g}}^{+}, \mathrm{A}^{2} \Pi_{\mathrm{u}}, \mathrm{B}^{2} \Sigma_{\mathrm{u}}^{+}$, $D^{2} \Pi_{g}$ and $C^{2} \Sigma_{u}^{+}$states are considered products. The lengths of the horizontal lines are proportional to Franck-Condon factors for electron removal from $\mathrm{N}_{2}\left(\mathrm{X}^{1} \Sigma_{\mathrm{g}}^{+}, v=0\right)$ molecules in vertical transitions (Lofthus and Krupenie 1977). The overlaps for the $\mathrm{D}^{2} \Pi_{\mathrm{g}}$ state are negligible at lower $v$ and only become appreciable at high $v$ and are not illustrated. Neuschäfer et al (1979) have observed optical emissions from lowenergy $\mathrm{Ar}^{2+}+\mathrm{N}_{2}$ collisions which they attribute to spontaneous radiative decay from the $\mathrm{N}_{2}^{+}\left(\mathrm{D}^{2} \Pi_{\mathrm{g}}\right)$ product state.

Two-electron transfer channels forming $\mathrm{N}_{2}^{2+}$ ions are given by the full curves in figure 5. The curve with asymptotic potential energy of -0.69 was computed using 
the $42.7 \mathrm{eV} \mathrm{N}_{2}^{2+}$ ionisation energy measured by Agee et al (1981) while the curve with $\Delta E$ at $0.27 \mathrm{eV}$ was obtained from laser photodissociation experiments of Cosby et al (1983). Diabatic transitions from the $\mathrm{Ar}^{2+}+\mathrm{N}_{2}$ curve to various $\mathrm{Ar}^{+}+\mathrm{N}_{2}^{+}$curves are possible at distances of several Ångstroms. These latter curves cross the $\mathrm{Ar}+\mathrm{N}_{2}^{2+}$ curves which can ultimately lead to two-electron transfer. The $\mathrm{N}_{2}^{2+}$ state examined by Cosby et al (1983) most likely has a ${ }^{1} \Sigma_{\mathrm{g}}^{+}$designation. Production of this state would be spin forbidden in $\mathrm{Ar}^{2+}\left({ }^{3} \mathrm{P}_{J}\right)+\mathrm{N}_{2}\left(\mathrm{X}^{1} \Sigma_{\mathrm{g}}^{+}, v=0\right)$ collisions but, as noted previously the Wigner rules may not be strictly applicable for heavy particle collisions.

The corresponding energies $(-\Delta E)$, at infinite internuclear separation distance. for reactions (1) and (2) involving molecular $\mathrm{O}_{2}, \mathrm{CO}, \mathrm{CO}_{2}, \mathrm{CH}_{4}$ and $\mathrm{C}_{2} \mathrm{H}_{6}$ systems are given in figure 6 by horizontal lines. Franck-Condon factors for forming various $v^{\prime}$ levels of the singly-charged product diatomic and triatomic ions from the $v^{\prime \prime}=0$ levels of the respective target molecules are given by the lengths of the horizontal lines. Broken curves indicate dissociation limits of the product ions. Franck-Condon factor envelopes for the polyatomic alkanes, obtained from photoion-photoelectron experiments and documented by Hedrick and Moran (1976), are given by the shaded areas. Energetic onsets for formation of doubly-charged ions are denoted by the

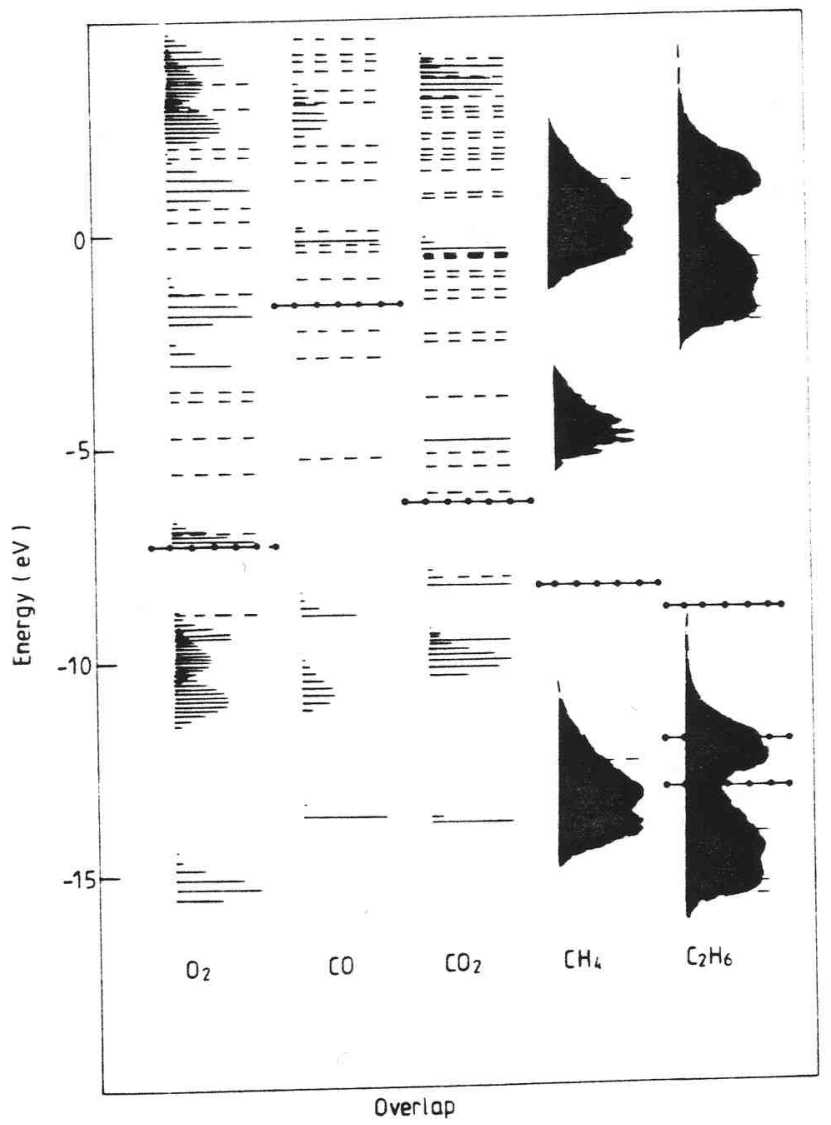

Figure 6. Energies $(\mathrm{eV})$ for electron transfer reactions of $\mathrm{Ar}^{2+}\left({ }^{3} \mathrm{P}_{J}\right)$ ions with neutral species $\mathrm{Y}\left(\mathrm{Y}=\mathrm{O}_{2}, \mathrm{CO}, \mathrm{CO}_{2}, \mathrm{CH}_{4}\right.$ and $\left.\mathrm{C}_{2} \mathrm{H}_{6}\right)$. Franck-Condon factors for $\mathrm{O}_{2}, \mathrm{CO}$ and $\mathrm{CO}_{2}$ are represented by the length of the horizontal lines. The $\mathrm{CH}_{4}$ and $\mathrm{C}_{2} \mathrm{H}_{6}$ FranckCondon factors are represented by shaded areas. 
curves with full circles. Doubly charged ionisation energies for $\mathrm{O}_{2}, \mathrm{CO}$ and $\mathrm{CO}_{2}$ have been taken from the compilation of Agee et al (1981). The $35.1 \mathrm{eV}$ vertical transition energy for forming $\mathrm{CH}_{4}^{2+}$ was taken from the work of Hanner and Moran (1981) who noted that this molecular ion is initially formed on a repulsive portion of the potential energy curve and undergoes spontaneous dissociation into single charged fragments. The minimum energies (Jones et al 1982) to form stable doubly-charged ions in the $\mathrm{C}_{2} \mathrm{H}_{6}$ system are: $30.3 \mathrm{eV}$ for $\mathrm{C}_{2} \mathrm{H}_{4}^{2+} ; 31.4 \mathrm{eV}$ for $\mathrm{C}_{2} \mathrm{H}_{5}^{2+}$ and $34.5 \mathrm{eV}$ for $\mathrm{C}_{2} \mathrm{H}_{3}^{2+}$.

\subsection{Reactant ion-beam state distribution}

Requisite for determination of charge transfer cross sections for different $\mathrm{Ar}^{2+}$ electronic states is the assessment of the incident ion-state distribution. Energies of various $\mathrm{Ar}^{2+}$ states have been tabulated (Moore 1949) and transition probabilities listed (Wiese et al 1969) for spontaneous radiative transitions of $\mathrm{Ar}^{2+}$ states. The energies to form the ground $\mathrm{Ar}^{2+}\left({ }^{3} \mathrm{P}_{J}\right)$ state and lower metastable $\mathrm{Ar}^{2+}\left({ }^{1} \mathrm{D}_{2}\right)$ and $\mathrm{Ar}^{2+}\left({ }^{1} \mathrm{~S}_{0}\right)$ states are $43.4,45.1$ and $47.5 \mathrm{eV}$ respectively. The lifetime of the $\mathrm{Ar}^{2+}\left({ }^{1} \mathrm{D}_{2}\right)$ state with respect to radiative ${ }^{1} \mathrm{D} \rightarrow{ }^{3} \mathrm{P}$ transitions is approximately $9 \mathrm{~s}$ while the $\mathrm{Ar}^{2+}\left({ }^{1} \mathrm{~S}_{0}\right)$ state has an approximate radiative lifetime of $0.1 \mathrm{~s}$ in ${ }^{1} \mathrm{~S} \rightarrow{ }^{1} \mathrm{D},{ }^{3} \mathrm{P}$ transitions. These lifetimes are sufficiently long for the ${ }^{1} \mathrm{D}_{2}$ and ${ }^{1} \mathrm{~S}_{0}$ states to be present in our reactant ion beam. Evidence for the production of these states in electron impact ionisation as well as their abundances and reactivities in different experimental systems are discussed below.

Low-energy non-resonant charge transfer cross sections for $\mathrm{Ar}^{2+}-\mathrm{He}$ reactions were observed by Maier and Stewart (1978) to increase as $\mathrm{Ar}^{2+}$ energies were lowered to several tenths of an electron volt, and these workers suggested this increase was probably caused by reactions involving metastable $\mathrm{Ar}^{2+}$ ions in their incident ion beam.

Johnsen and Biondi (1978a, b) used a drift-tube mass spectrometric apparatus to measure mobilities and thermal rate constants for $\mathrm{Ar}^{2+}$-rare-gas interactions. They measured varying mobilities for a given reactant ion-atom system and indicated that different mobility groups resulted from reactions of different $\mathrm{Ar}^{2+}$ electronic states which they associated with the ${ }^{3} \mathrm{P}_{J},{ }^{1} \mathrm{D}_{2}$ and ${ }^{1} \mathrm{~S}_{0}$ states. Neuschäfer et al (1979) used a flow-drift-tube apparatus to measure the thermal $\mathrm{Ar}^{2+}\left({ }^{3} \mathrm{P}_{J}\right)$ and $\mathrm{Ar}^{2+}\left({ }^{1} \mathrm{~S}_{0}\right)$ charge transfer reactions with nitrogen molecules. They suggest that reactant $\mathrm{Ar}^{2+}$ ions are formed in the ${ }^{3} \mathrm{P}_{J},{ }^{1} \mathrm{D}_{2}$ and ${ }^{1} \mathrm{~S}_{0}$ states in the statistical ratio of $9: 5: 1$ by electron impact ionisation of argon gas. Störi et al (1979) used the same flow-drift-tube apparatus to determine thermal charge transfer rate constants for reactions of $\mathrm{Ar}^{2+}\left({ }^{3} \mathrm{P}_{J}\right)$ and $\mathrm{Ar}^{2+}\left({ }^{1} \mathrm{~S}_{0}\right)$ ions with diatomic and polyatomic molecules. Smith et al $(1979,1980$ employed a selected ion flow tube to measure rate coefficients for reactions of $\mathrm{Ar}^{2-}\left({ }^{3} \mathrm{P}_{J}\right)$ and $\mathrm{Ar}^{2+}\left({ }^{1} \mathrm{~S}_{0}\right)$ states with a number of atoms and molecules at thermal energies. Holzscheiter and Church (1981) examined the reactions of $\mathrm{Ar}^{2+}$ with $\mathrm{N}_{2}$ at very low pressures using a stored-ion technique. In this latter work, reactant ions were produced by electron impact ionisation and stored for several seconds in an ion trap, a time interval long enough to permit radiative decay of the $\mathrm{Ar}^{2+}\left({ }^{1} \mathrm{~S}_{0}\right)$ state but short compared with the $\mathrm{Ar}^{2+}\left({ }^{1} \mathrm{D}_{2}\right)$ radiative lifetime. Thus, they were able to selectively measure the $\mathrm{Ar}^{2+}\left({ }^{1} \mathrm{D}_{2}\right)-\mathrm{N}_{2}$ reactions without interferences from $\mathrm{Ar}^{2+}\left({ }^{1} \mathrm{~S}_{0}\right)$ state ions.

Kamber et al (1982) measured both the elastic and inelastic differential $\mathrm{Ar}^{2+}-\mathrm{Ne}$ charge transfer cross sections at $0.54 \mathrm{keV}$. Their zero-angle energy-loss spectra for single-electron transfer processes illustrated transitions involving both ground $\mathrm{Ar}^{2+}\left({ }^{3} \mathrm{P}_{J}\right)$ and metastable $\mathrm{Ar}^{2+}\left({ }^{1} \mathrm{D}_{2}\right)$ states in the reactant ion beam. 
Matsumoto et al (1982) used an elegant optical attentuation technique to determine the fraction of metastable $\mathrm{Ar}^{2+}\left({ }^{1} \mathrm{D}_{2}\right)$ state in an $\mathrm{Ar}^{2+}$ ion beam produced by electron impact ionisation. They extended the beam attenuation method of Turner et al (1968) to the attenuation of specific emission lines from excited $\mathrm{Ar}^{*+}$ charge transfer products in $\mathrm{Ar}^{2+}-\mathrm{Na}$ reactions. Combining the beam and optical attenuation methods, Matsumoto et al (1982) detemined the ${ }^{1} \mathrm{D}_{2}$ state abundance to be $0.29 \pm 0.16$ which is in harmony with abundances estimated from statistical weights of the $\mathrm{Ar}^{2+}\left({ }^{3} \mathrm{P}_{J},{ }^{1} \mathrm{D}_{2}\right.$ and ${ }^{1} \mathrm{~S}_{0}$ ) states. Thus, we have assumed our $\mathrm{Ar}^{2+}$ reactant ions to be primarily in the ${ }^{3} \mathrm{P}_{J}$, ${ }^{1} \mathrm{D}_{2}$ and ${ }^{1} \mathrm{~S}_{0}$ states with relative abundances of $0.60,0.33$ and 0.07 respectively.

A small fraction $(2-4 \%)$ of the $\mathrm{Ar}^{2+}$ ions in our reactant beam may occupy higher excited states. Varga and Winter (1978) found eivdence of these higher metastable states in their measurements of yields and energy distributions of secondary electrons ejected by $\mathrm{Ar}^{2+}$ impact on a clean polycrystalline tungsten target. The secondary electron yield was found to be sensitive to a high-lying metastable component in the $\mathrm{Ar}^{2+}$ beam produced above $50 \mathrm{eV}$. An increase in the secondary electron yield in the $60-70 \mathrm{eV}$ ionising electron energy range provided evidence of metastable $\mathrm{Ar}^{2+}$ $\left(3 \mathrm{~d}^{5} \mathrm{D}^{\circ}\right.$ and $\left.3 \mathrm{~d}^{3} \mathrm{~F}^{\circ}\right)$ states which have appearance energies of 61.4 and $66.5 \mathrm{eV}$ respectively. The abundance of these higher metastable states was estimated to be 1.8 to $3.8 \%$ of the toal number of ions in an $\mathrm{Ar}^{2+}$ beam produced by $80 \mathrm{eV}$ electron impact ionisation of Ar. Our examination of one- and two-electron transfer cross sections as a function of electron energy used to form the reactant $\mathrm{Ar}^{2+}$ beam gave no evidence for the presence of these higher metastable states in our reactant ion beam.

\subsection{Cross sections for $\mathrm{Ar}^{2+}\left({ }^{3} \mathrm{P}\right)$ and $\mathrm{Ar}^{2+}$ (metastable) reactant ions}

Total cross sections for one- and two-electron transfers in the collisions of $\mathrm{Ar}^{2+}$ with a variety of target species have been determined for reactant ions formed by $90 \mathrm{eV}$

Table 1. Total charge transfer cross sections for the reaction $\mathrm{Ar}^{2+}$ (all states) $+\mathrm{Y} \rightarrow$ $\mathrm{Ar}^{0}+\mathrm{Y}^{2+}$.

\begin{tabular}{lrrrrrr}
\hline & \multicolumn{5}{c}{ Cross sections $\left(10^{-16} \mathrm{~cm}^{2}\right)$} \\
\cline { 2 - 7 } $\begin{array}{l}\text { Ion kinetic } \\
\text { energy }(\mathrm{eV})\end{array}$ & $\mathrm{Y}=\mathrm{O}_{2}$ & $\mathrm{~N}_{2}$ & $\mathrm{CO}$ & $\mathrm{CO}_{2}$ & $\mathrm{CH}_{4}$ & $\mathrm{C}_{2} \mathrm{H}_{6}$ \\
\hline 7000 & 1.3 & 1.8 & 2.6 & 5.6 & 1.3 & 4.0 \\
6800 & 1.2 & 1.8 & 2.5 & 5.3 & 0.9 & 4.2 \\
6600 & 1.2 & 1.8 & 2.4 & 5.2 & 0.9 & 4.4 \\
6400 & 1.2 & 1.8 & 2.2 & 5.1 & 0.9 & 4.4 \\
6200 & 1.3 & 1.8 & 2.3 & 4.7 & 1.0 & 4.5 \\
6000 & 1.3 & 1.7 & 2.2 & 4.9 & 0.9 & 4.5 \\
5800 & 1.2 & 1.8 & 2.1 & 4.5 & 1.0 & 4.5 \\
5600 & 1.1 & 1.8 & 2.1 & 4.4 & 1.1 & 4.5 \\
5400 & 1.1 & 1.7 & 2.0 & 4.2 & 1.0 & 4.6 \\
5200 & 1.1 & 1.8 & 2.0 & 4.1 & 1.2 & 5.1 \\
5000 & 1.4 & 1.8 & 1.9 & 3.7 & 1.3 & 5.3 \\
4800 & 0.8 & 1.3 & 1.9 & 3.6 & 0.9 & 4.7 \\
4600 & 1.0 & 1.5 & 2.1 & 3.8 & 1.2 & 5.1 \\
4400 & 1.0 & 1.4 & 2.1 & 3.7 & 1.1 & 5.0 \\
4200 & 1.1 & 1.1 & 2.2 & 3.5 & 1.3 & 5.2 \\
4000 & 1.5 & 1.5 & 2.3 & 3.5 & 2.1 & 6.4 \\
\hline
\end{tabular}


Table 2. Total charge transfer cross sections for the reaction $\mathrm{Ar}^{2+}$ (all states) $+\mathrm{Y} \rightarrow$ $\mathrm{Ar}^{+}+\mathrm{Y}^{+}$.

\begin{tabular}{lrrrrrr}
\hline & \multicolumn{5}{c}{ Cross sections $\left(10^{-16} \mathrm{~cm}^{2}\right)$} \\
\cline { 2 - 7 } Ion kinetic \\
\cline { 2 - 7 } & $\mathrm{Y}=\mathrm{O}_{2}$ & $\mathrm{~N}_{2}$ & $\mathrm{CO}$ & $\mathrm{CO}_{2}$ & $\mathrm{CH}_{4}$ & $\mathrm{C}_{2} \mathrm{H}_{6}$ \\
\hline 7000 & 2.3 & 1.8 & 1.8 & 1.9 & 1.6 & 3.3 \\
6800 & 2.3 & 1.7 & 1.9 & 1.8 & 1.6 & 3.3 \\
6600 & 2.3 & 1.8 & 1.9 & 1.9 & 1.7 & 3.4 \\
6400 & 2.2 & 1.8 & 1.7 & 1.8 & 1.7 & 3.6 \\
6200 & 2.3 & 1.8 & 1.8 & 1.7 & 1.8 & 3.5 \\
6000 & 2.3 & 1.8 & 1.7 & 1.8 & 1.7 & 3.6 \\
5800 & 2.3 & 1.8 & 1.8 & 1.8 & 1.8 & 3.6 \\
5600 & 2.3 & 1.9 & 1.8 & 1.7 & 1.9 & 3.8 \\
5400 & 2.3 & 1.9 & 1.8 & 1.7 & 2.0 & 4.1 \\
5200 & 2.4 & 2.0 & 1.8 & 1.7 & 2.1 & 4.5 \\
5000 & 2.4 & 2.0 & 1.7 & 1.6 & 2.2 & 4.6 \\
4800 & 2.5 & 2.1 & 1.8 & 1.5 & 2.1 & 4.6 \\
4600 & 2.5 & 2.1 & 1.6 & 1.5 & 2.2 & 5.2 \\
4400 & 2.6 & 2.3 & 1.7 & 1.4 & 2.2 & 5.1 \\
4200 & 2.2 & 2.0 & 1.5 & 1.2 & 2.0 & 4.5 \\
4000 & 1.7 & 1.6 & 1.2 & 1.2 & 1.9 & 3.9 \\
\hline
\end{tabular}

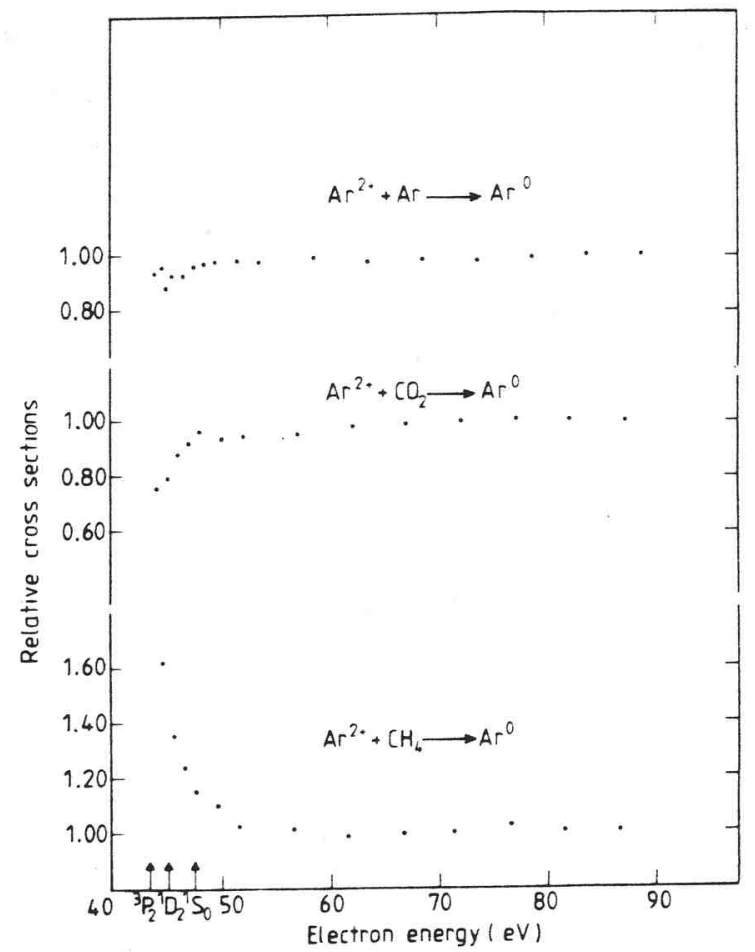

Figure 7. Relative cross section for $\mathrm{keV} \mathrm{Ar}{ }^{2+}+\mathrm{Y} \rightarrow \mathrm{Ar}^{0}+(\mathrm{Y})^{2+}$ charge transfer reactions forming fast $\mathrm{Ar}^{0}$ as a function of electron energy used to produce the reactant beam of $\mathrm{Ar}^{2+}$ ions. Results for different reactant systems with $\mathrm{Y}=\mathrm{Ar}, \mathrm{CO}_{2}$ and $\mathrm{CH}_{4}$ are given in the respective upper, middle and lower portions of this figure. 


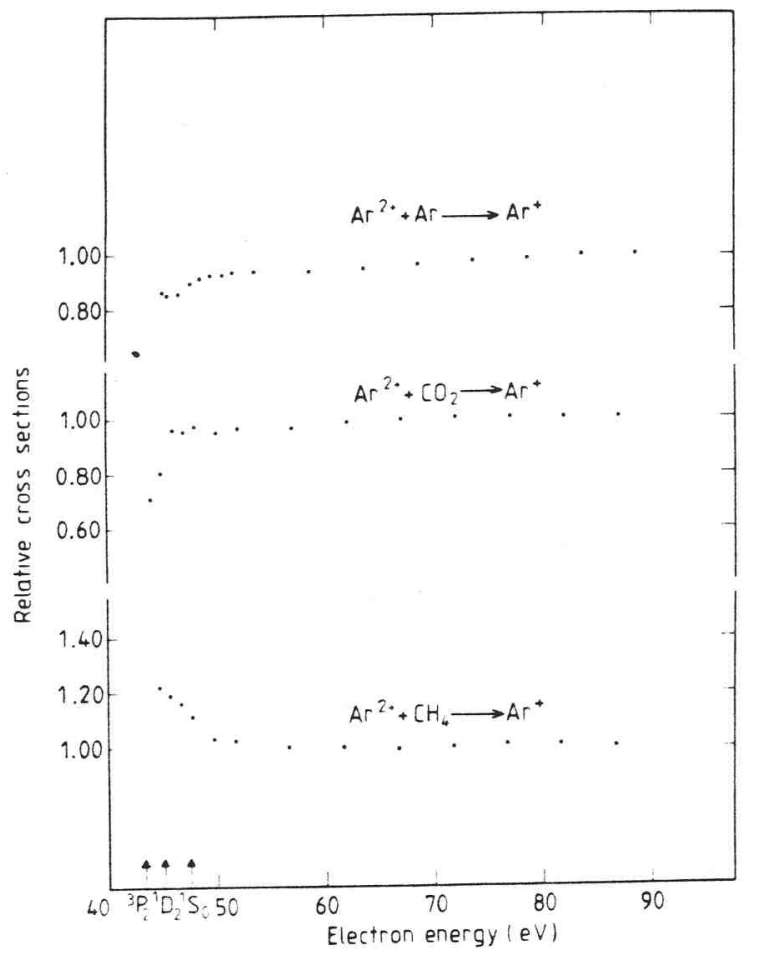

Figure 8. Relative cross sections for $\mathrm{keV} \mathrm{Ar} r^{2+}+\mathrm{Y} \rightarrow \mathrm{Ar}^{+}+(\mathrm{Y})^{+}$charge transfer reactions forming $\mathrm{Ar}^{+}$as a function of electron energy used to produce the reactant beam of $\mathrm{Ar}^{2-}$ ions. Results for different reactant systems with $\mathrm{Y}=\mathrm{Ar}, \mathrm{CO}_{2}$ and $\mathrm{CH}_{4}$ are given in the respective upper, middle and lower portions of this figure.

electron impact ionisation. Cross sections for two-electron transfer reactions of 4.000 to $7.000 \mathrm{keV} \mathrm{Ar}{ }^{2+}$ ions with $\mathrm{O}_{2}, \mathrm{~N}_{2}, \mathrm{CO}, \mathrm{CO}_{2}, \mathrm{CH}_{4}$ and $\mathrm{C}_{2} \mathrm{H}_{6}$ are given in table 1 . Several features are evident from the data in this table: (i) the two-electron transfer cross sections are approximately constant from 4 to $7 \mathrm{keV}$ ion energies; (ii) cross sections measured in each of the systems are of the same order of magnitude and range from 0.8 to $6.4 \times 10^{-16} \mathrm{~cm}^{2}$.

Single-electron transfer total cross sections for reactions of $\mathrm{Ar}^{2+}$ with $\mathrm{O}_{2}, \mathrm{~N}_{2}, \mathrm{CO}$, $\mathrm{CO}_{2}, \mathrm{CH}_{4}$ and $\mathrm{C}_{2} \mathrm{H}_{6}$ are given in table 2. These one-electron transfer cross sections show little variation with ion kinetic energy and cross sections range from 1.2 to $5.2 \times 10^{-16} \mathrm{~cm}^{2}$ in the different systems. The magnitudes of one- and two-electron transfer cross sections are somewhat similar and the ratios of double- to single-electron transfer cross sections, averaged over the $4-7 \mathrm{keV}$ incident ion kinetic energies, are $0.52,0.88,1.27,2.66,0.60,1.20$ for the respective $\mathrm{O}_{2}, \mathrm{~N}_{2}, \mathrm{CO}, \mathrm{CO}_{2}, \mathrm{CH}_{4}, \mathrm{C}_{2} \mathrm{H}_{6}$ systems.

The influences of excited states in the reactant ion beam are illustrated in figure 7 where relative two-electron transfer cross sections are presented as a function of electron energy used to produce the reactant ions. A similar presentation of relative single-electron transfer cross sections as a function of ionising electron energy is given in figure 8. The energetic onsets for forming ground state ${ }^{3} \mathrm{P}_{2}$ and metastable ${ }^{1} \mathrm{D}_{2}$, ${ }^{1} \mathrm{~S}_{0} \mathrm{Ar}^{2+}$ reactant ion states are indicated by arrows on the bottom of this figure. 


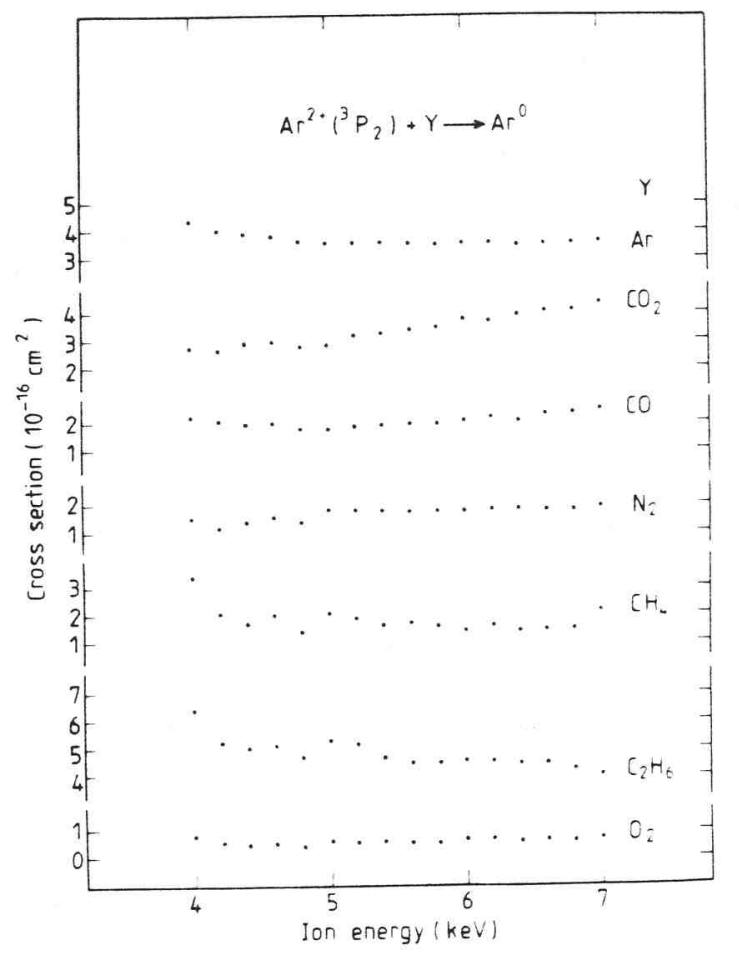

Figure 9. Charge transfer cross sections $\left(10^{-16} \mathrm{~cm}^{2}\right)$ for production of fast neutral product $\mathrm{Ar}^{0}$ as a function of reactant ion kinetic energy $(\mathrm{keV})$ in $\mathrm{Ar}^{2+}\left({ }^{3} \mathrm{P}_{2}\right.$ ground state $)+\mathrm{Y}$ interactions. The target gas $Y$ used in each collision system is listed on the right-hand side of the figure.

Increases in relative cross sections for both the $\mathrm{Ar}^{2+}+\mathrm{Ar}$ and $\mathrm{Ar}^{2+}+\mathrm{CO}_{2}$ reactions are observed in figures 7 and 8 as the $\mathrm{Ar}^{2+}$ excited-state population is raised by increasing the energy of the ionising electrons. Cross sections, $\sigma\left({ }^{3} \mathrm{P}\right)$, for reactions of ground-state $\mathrm{Ar}^{2+}\left({ }^{3} \mathrm{P}\right)$ ions have been determined from data taken below the energy threshold for forming $\mathrm{Ar}^{2+}\left({ }^{1} \mathrm{D}_{2}\right)$ ions. Cross sections for two-electron transfer in $\mathrm{Ar}^{2+}\left({ }^{3} \mathrm{P}\right)$ ground-state reactions are illustrated in figure 9 for the different collision systems. The corresponding single-electron transfer cross sections for $\mathrm{Ar}^{2+}\left({ }^{3} \mathrm{P}\right)$ ion reactions are presented in figure 10 as a function of incident ion kinetic energy .

The ratios of ${ }^{3} \mathrm{P}$ state cross sections to total cross section $\sigma_{\mathrm{T}}$ (all states) for reactions of $\mathrm{Ar}^{2+}$ ions produced by $80 \mathrm{eV}$ electron impact ionisation are given in table 3 . In each collision system the ratio values of (ground state/all states) cross sections are similar for both the one- and two-electron transfer processes. Both thermal energy rate coefficients (Smith et al 1979) and the $\mathrm{keV}$ electron transfer cross sections, measured in the present investigation, for $\mathrm{Ar}^{2+}-\left(\mathrm{N}_{2}, \mathrm{O}_{2}, \mathrm{CO}_{2}\right)$ systems are slightly larger for reactions involving excited-state ions than for ground-state $\mathrm{Ar}^{2+}\left({ }^{3} \mathrm{P}\right)$ ions. Although one- and two-electron transfer cross sections are approximately equal at $\mathrm{keV}$ energies, the single- and double-electron transfer channels are not observed as competitive parallel processes in molecular systems at thermal energies. Exother$\mathrm{mic} /$ thermoneutral double electron transfer processes dominate the thermal energy $\mathrm{Ar}^{2+}\left({ }^{3} \mathrm{P}\right.$ and $\left.{ }^{1} \mathrm{~S}\right)-\left(\mathrm{N}_{2}, \mathrm{O}_{2}, \mathrm{CO}_{2}\right)$ reactions and lead to the formation of doubly-charged 


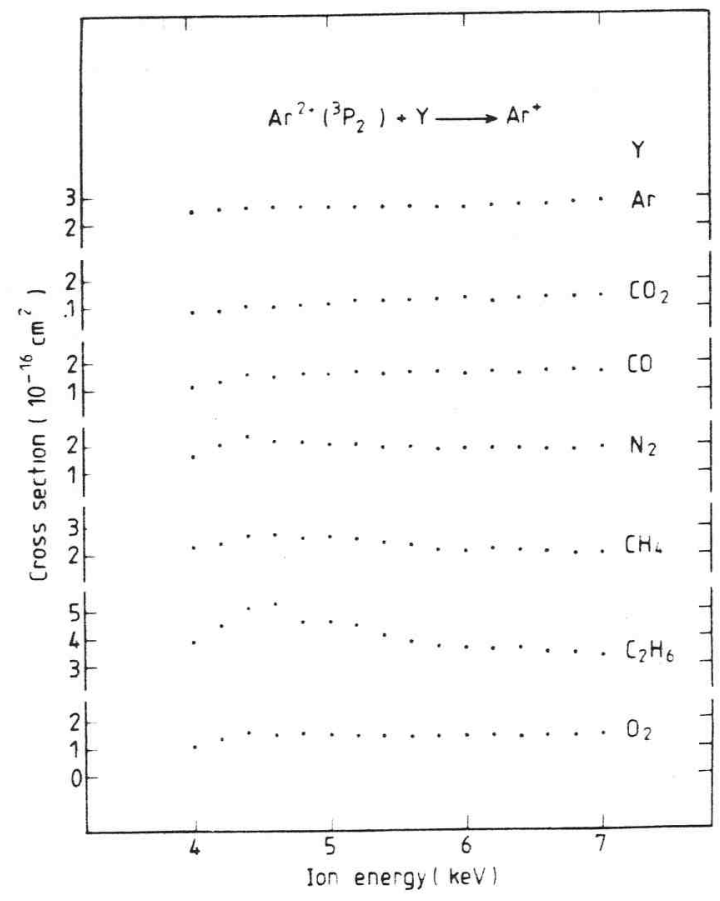

Figure 10. Charge transfer cross sections $\left(10^{-16} \mathrm{~cm}^{2}\right)$ for production of fast product $\mathrm{Ar}^{+}$ as a function of reactant ion kinetic energy $(\mathrm{keV})$ in $\mathrm{Ar}^{2-}\left({ }^{3} \mathrm{P}_{2}\right.$ ground state $)+\mathrm{Y}$ interactions The target gas $\mathrm{Y}$ used in each collision system is listed on the right-hand side of the figure.

Table 3. Relative ratio of the ground-state cross section $\left(\sigma_{\mathbf{g}}\left({ }^{3} \mathrm{P}\right)\right)$ to the total cross section $\left(\sigma_{\mathrm{T}}(\right.$ all states $\left.)\right)$ for the reactions:

$$
\mathrm{Ar}^{2+}+\mathrm{Y} \longrightarrow \mathrm{Ar}^{0}+(\mathrm{Y})^{2+}
$$

\begin{tabular}{lll}
\hline & \multicolumn{2}{c}{$\sigma_{\mathbf{B}}\left({ }^{3} \mathrm{P}\right) / \sigma_{\mathrm{T}}($ all states $)$} \\
\cline { 2 - 3 } $\mathrm{Y}$ & Reaction $(a)$ & Reaction $(b)$ \\
\hline $\mathrm{Ar}$ & 0.92 & 0.85 \\
$\mathrm{O}_{2}$ & 0.50 & 0.60 \\
$\mathrm{~N}_{2}$ & 0.98 & 1.0 \\
$\mathrm{CO}$ & 0.94 & 0.90 \\
$\mathrm{CO}_{2}$ & 0.77 & 0.72 \\
$\mathrm{CH}_{4}$ & 1.55 & 1.22 \\
$\mathrm{C}_{2} \mathrm{H}_{6}$ & 1.00 & 1.00 \\
\hline
\end{tabular}

molecular ions which spontaneously decompose into single-charged fragments. The data in table 3 show that factors which lead to increases in single-electron transfer cross sections at $\mathrm{keV}$ energies also lead to increases in double-electron transfer cross sections. This association is not surprising since single- and double-electron transfer product channels are coupled to one another through diabatic transitions between potential curves for the single-electron transfer exothermic product channels and 
curves for the double-electron transfer channels. For example, the $\operatorname{Ar}^{2+}\left({ }^{3} \mathrm{P}\right)+\operatorname{Ar}\left({ }^{1} \mathrm{~S}\right)$ reactant curve in figure 3 crosses the $\operatorname{Ar}^{+}\left({ }^{2} \mathrm{P}\right)+\mathrm{Ar}^{+}\left({ }^{2} \mathrm{P}\right)$ product curve at $1.7 \times 10^{-8} \mathrm{~cm}$ which in turn crosses the $\operatorname{Ar}\left({ }^{1} \mathrm{~S}\right)+\mathrm{Ar}^{2+}\left({ }^{1} \mathrm{D}\right)$ curve at $1.6 \times 10^{-8} \mathrm{~cm}$. The argon system is unique from all the others examined in this investigation since resonant two-electron transfer processes are possible. Curve crossings between one- and two-electron transfer product channels are indicated in the $\mathrm{Ar}^{2+}\left({ }^{3} \mathrm{P}\right)+\mathrm{N}_{2}\left(\mathrm{X}^{1} \Sigma_{\mathrm{g}}\right)$ reaction shown in figure 5. Multiple curve crossings can also couple the one- and two-electron transfer channels in the other polyatomic systems illustrated in figure 6.

Cross sections, $\sigma$ (excited states), for reactions of $\mathrm{Ar}^{2+}$ metastable states have been determined from the relation

$$
\sigma(\text { excited states })=\left(\sigma_{T}(\text { all states })-f_{g} \sigma\left({ }^{3} \mathrm{P}\right)\right) / f_{\text {exc }}
$$

where $\sigma\left({ }^{3} \mathrm{P}\right)$ is the cross section involving ground-state ions and $\sigma_{\mathrm{T}}$ (all states) is the total measured cross section for reactions of $\mathrm{Ar}^{2+}$ ions with a ${ }^{3} \mathrm{P},{ }^{1} \mathrm{D}_{2},{ }^{1} \mathrm{~S}_{0}$ state distribution characteristic of $90 \mathrm{eV}$ electron impact ionisation. The fraction $(0.40)$ of the ion beam in these metastable states is denoted as $f_{\text {exc }}$ and the fraction $(0.60)$ in the ${ }^{3} \mathrm{P}$ ground state is represented by $f_{\mathrm{g}}$. Two-electron transfer cross sections involving excited-state ions were determined from equation (8) at various incident ion energies and the results are presented in figure 11 . Single-electron transfer cross sections for excited-state $\mathrm{Ar}^{2+}$ ions were determined from equation (8) and t're results are shown

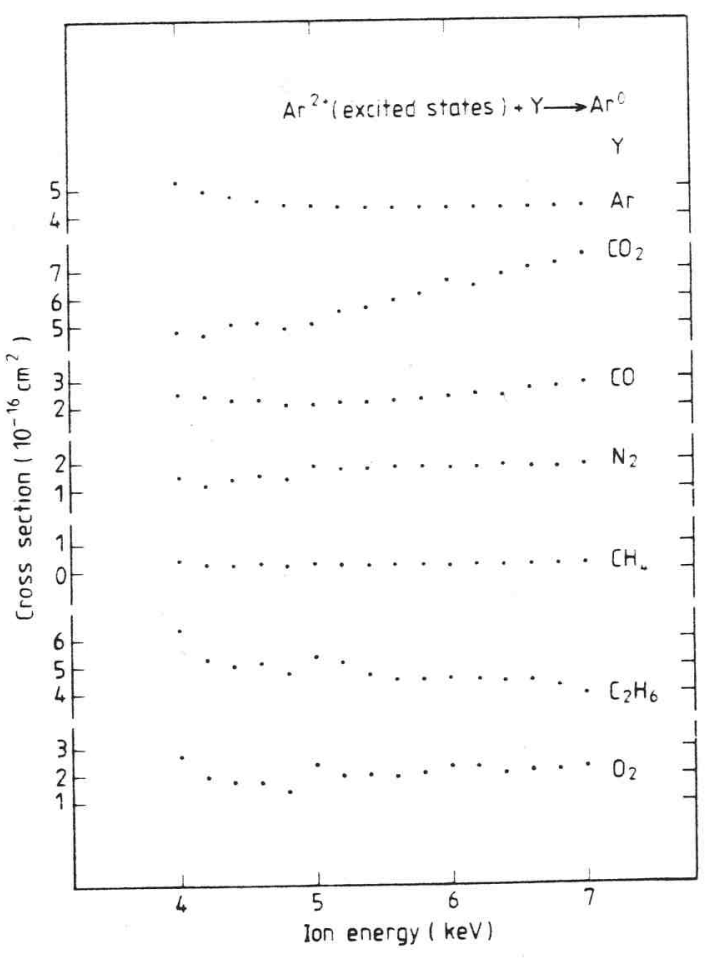

Figure 11. Charge transfer cross sections $\left(10^{-16} \mathrm{~cm}^{2}\right)$ for production of fast neutral $\mathrm{Ar}^{0}$ as a function of reactant ion kinetic energy $(\mathrm{keV})$ in $\mathrm{Ar}^{2+}\left({ }^{1} \mathrm{D}_{2},{ }^{1} \mathrm{~S}_{0}\right.$ excited states) $+\mathrm{Y}$ interactions. The target gas $Y$ used in each collision system is listed on the right-hand side of the figure. 
in figure 12 as a function of ion kinetic energy for the different collision systems. Cross sections for excited-state reactions are in the range of 1 to $7 \times 10^{-16} \mathrm{~cm}^{2}$. In general, excited-state cross sections for single- and double-electron transfer processes in individual systems are similar in magnitude and can be attributed in part to favourable curve crossings between the reactant and exothermic single-electron transfer channels which in turn cross those for the double-electron transfer channels.

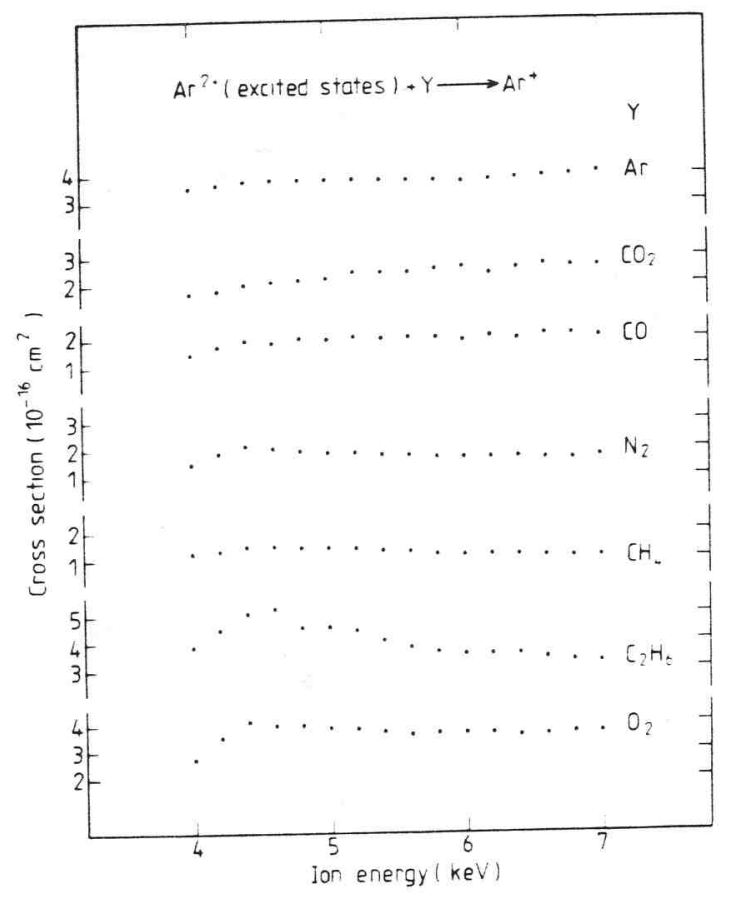

Figure 12. Charge transfer cross sections $\left(10^{-16} \mathrm{~cm}^{2}\right)$ for production of fast product $\mathrm{Ar}$ as a function of reactant ion kinetic energy ( $\mathrm{keV}$ ) in $\mathrm{Ar}^{2-}\left({ }^{1} \mathrm{D}_{2},{ }^{1} \mathrm{~S}_{1}\right.$ excited state $-\mathrm{Y}$ interactions. The target gas $\mathrm{Y}$ used in each collision system is listed on the right-hand side of the figure.

\section{References}

Agee J H, Wilcox J B, Abbey L and Moran T F 1981 Chem. Phys. 61 171-79

Ast T, Terwilliger D T, Beynon J H and Cooks R G 1975 J. Chem. Phys. 62 3855-63

Barrett J L and Leventhal J J 1981 Phys. Rev. A 23 485-90

Cosby P C, Möller R and Helm H 1983 Phys. Rev. A in press

Cosby P C and Moran T F 1972 J. Chem. Phys. 57 3569-70

Hanner A W and Moran T F 1981 Org. Mass Spectrom. 16 512-3

Hasted J B and Hussain M 1964 Proc. Phys. Soc. 83 911-24

Hayden H and Utterback N G 1964 Phys. Rev. 135 A1575-79

Hedrick A F and Moran T F 1976 J. Chem. Phys. 64 1858-60

Holzscheiter H M and Church D A $1981 \mathrm{~J}$. Chem. Phys. 74 2313-8

Janev R K and Presnyakov L P 1981 Phys. Rep. 70 1-107

Johnsen R and Biondi M A 1978a Phys. Rev. A 18 989-95

1978b Phys. Rev. A $18996-1003$

- 1979 Phys. Rev. A $2087-97$ 
Jones B E, Abbey L E, Chatham H L, Hanner A W, Teleshefsky L, Burgess E M and Moran T F 1982 Org. Mass Spectrom. 17 10-8

Kadota K, Dijkkamp D, van der Woude R L, de Boer A, Pan Guang Yan and de Heer F J 1982 J. Phys. B: At. Mol. Phys. 15 3275-96

Kamber E Y, Mathur D and Hasted J B 1982 J. Phys. B: At. Mol. Phys. 15 263-73

Kaneko Y, Iwai T, Ohtani S, Okuno K, Kobayashi N, Tsurubuchi S, Kimura M and Tawara H $1981 \mathrm{~J}$. Phys. B: At. Mol. Phys. 14 881-91

Latypov Z Z, Fedorenko N V, Flaks I P and Shaporenko A A 1969 Sov. Phys.-JETP 28 439-42

Lofthus A and Krupenie P H 1977 J. Phys. Chem. Ref. Data 6 113-307

McGowan J W and Kerwin L 1967 Can. J. Phys. 45 1451-67

Maier W B and Stewart B $1978 \mathrm{~J}$. Chem. Phys. 68 4228-32

Matsumoto A, Ohtani S and Iwai T 1982 J. Phys. B: At. Mol. Phys. 15 1871-81

Matsumoto A, Tsurubuchi S, Iwai T, Ohtani S, Okuno K and Kaneko Y 1980 J. Phys. Soc. Japan 48 575-82 Moore C E 1949 Atomic Energy Levels NBS Circular No 467 (Washington, DC: US Govt Printing Office) Moore J H 1974 Phys. Rev. A $10724-5$

Moran T F and Wilcox J B 1978 J. Chem. Phys. 69 1397-405

Neuschäfer D, Ottinger Ch, Zimmermann S, Lindinger W, Howorka F and Störi H 1979 Int. J. Mass Spectrom. Ion Phys. 31 345-65

Salzborn E and Müller A 1980 Proc 11th Int. Conf. on Physics of Electronic and Atomic Collisions, Kyoto ed N Oda and K Takayanagi (Amsterdam: North-Holland) Invited Papers and Progress Reports pp 407-26

Smith D, Adams N G, Alge E, Villinger H and Lindinger W 1980 J. Phys. B: At. Mol. Phys. 13 2787-99 Smith D, Grief D and Adams N G 1979 Int. J. Mass Spectrom. Ion Phys. 30 271-83

Störi H, Alge E, Villinger H, Egger F and Lindinger W 1979 Int. J. Mass Spectrom. Ion Phys. 30 263-70

Turner B R, Rutherford J A and Compton D M J 1968 J. Chem. Phys. 48 1602-8

Varga P and Winter H 1978 Phys. Rev. A $182453-8$

Wiese W L, Smith M W and Miles B M 1969 Atomic Transition Probabilities vol 2 NSRDS-NBS 22 (Washington, DC: US Govt Printing Office) 